Meta

Journal des traducteurs

Translators' Journal

\title{
Translation Theory: Where Are We Going?
}

\section{Roger T. Bell}

Volume 32, numéro 4, décembre 1987

URI : https://id.erudit.org/iderudit/002052ar

DOI : https://doi.org/10.7202/002052ar

Aller au sommaire du numéro

\section{Éditeur(s)}

Les Presses de l'Université de Montréal

ISSN

0026-0452 (imprimé)

1492-1421 (numérique)

Découvrir la revue

Citer cet article

Bell, R. T. (1987). Translation Theory: Where Are We Going? Meta, 32(4),

403-415. https://doi.org/10.7202/002052ar

\section{Résumé de l'article}

In this paper it is asserted that, despite recent movements in continental translation theory (see Wilss $1982: 59$, for an admirable summary of the situation), the essential orientation of translation theory, in the English-speaking world in particular, is still towards the evaluation of translation as product (i.e. as the translated text) and, by means of such evaluation, towards the discovery or creation of a set of normative maxims for the production of the ideal translation. What is proposed is a shift of focus away from the translation as an artifact - a product - towards translating as process $\mathrm{i}$. e. an investigation of the psycholinguistic mechanisms of decoding and encoding in the context of bi- rather than monolingual information exchange. The paper concludes with some tentative hints at parts of the decoding elements of a model of translating which, it is hoped, will help to orient translators and teachers towards the means by which texts are transferred from language to language and from speech community to speech community; a process which is universally recognized as a sine qua non for the improvement of international relations in a sadly divided world.
Ce document est protégé par la loi sur le droit d'auteur. L’utilisation des services d’Érudit (y compris la reproduction) est assujettie à sa politique d'utilisation que vous pouvez consulter en ligne.

https://apropos.erudit.org/fr/usagers/politique-dutilisation/ 


\section{TRANSLATION THEORY : WHERE ARE WE GOING ?}

ROGER T. BELL

Faculty of Languages, The Polytechnic of Central London, London. U.K.

\section{ABSTRACT}

In this paper it is asserted that, despite recent movements in continental translation theory (see Wilss 1982 : 59, for an admirable summary of the situation), the essential orientation of translation theory, in the English-speaking world in particular, is still $^{1}$ towards the evaluation of translation as product (i.e. as the translated text) and, by means of such evaluation, towards the discovery or creation of a set of normative maxims for the production of the ideal translation.

What is proposed is a shift of focus away from the translation as an artifact - a product - towards translating as process i.e. an investigation of the psycholinguistic mechanisms of decoding and encoding in the context of bi- rather than monolingual information exchange.

The paper concludes with some tentative hints at parts of the decoding elements of a model of translating which, it is hoped, will help to orient translators and teachers towards the means by which texts are transferred from language to language and from speech community to speech community; a process which is universally recognized as a sine qua non for the improvement of international relations in a sadly divided world.

\section{TRANSLATION THEORY : THE BACKGROUND TO THE PROBLEM}

Writing on translation theory in English still appears to be dominated by principles formulated nearly two centuries ago (by Tytler 1791) and typified by the title of the first chapter of his book : "Description of a good translation ; general rules flowing from that description" (Tytler op. cit. : 7). From this has arisen a programme of analysis, comparison and evaluation which has had as its goal the specification of a set of rules or maxims of a profoundly normative character. The essential prescriptivism of such an approach, linked, as it can often be, with an inadequate knowledge and understanding of the techniques and findings of contemporary linguistics ${ }^{2}$ has had the unfortunate effect of cutting translation theory off from the mainstream of academic enquiry in the field of human communication. Not that it is surprising given the bluntly antiintellectual stance taken by some translation theorists declaring translation to be a "craft" and denying the very possibility of the creation of a "single valid comprehensive theory of translation" (Newmark 1982 : 113). Small wonder that, presented in such a way, translation theory has failed to attract sympathetic attention and interest from scholars working in linguistics itself ${ }^{3}$.

No doubt the inherent prescriptivism can be traced back to past preoccupations - the translation of the Classics and the Bible - but now, in the last 15 years of the 20 th century, it is becoming abundantly clear that technological progress, the enhancement of harmonious relations between communities and individuals and, maybe, the very survival of humanity depend crucially on the exchange of knowledge and skills both of which depend on a more sophisticated approach to translation. 
What is desperately needed now, and needed fast, in an approach to translation which maximizes the individuality of the process ${ }^{4}$, probes the phenomenon as it takes place in the mind of the translator and seeks to build, on the basis of models of the process, an explanation of what it means to translate. Such models would form part of an approach in applied linguistics (see Bell $1981: 75-78$ ) or, alternatively, part of a linguistique de parole in constrast with present theories of linguistics which are, in essence, a linguistique de langue (Wilss op. cit. : 13-112). To accept either of these views would be not only to open up the rich storehouse of linguistics to the translator and provide the linguist with an ideal test-bed for theory (both in themselves extremely important results) but also allow us to take a major step towards an integrated theory of langage of the type called for by de Saussure (1916:33) under the term sémiologie.

Perhaps such a theory would have the effect of affecting a reconciliation between translation theory and modern linguistics in much the same way as sociolinguistics has provided the means for the incorporation of dialectology during the last twenty years or so (see Bell 1976 : 24). In addition, such a theory might well enrich linguistics (as sociolinguistics has, with its insistence on the centrality of variation) by providing insights into cross-cultural semantics and pragmatics ; a potential movement towards the discovery of the elusive "universals" we seek in human language. There is, clearly, much to be gained from an open-minded reassessment of the place of translation theory in the human sciences as a whole, and in linguistics in particular.

\section{TRANSLATION : PROCESS AND PRODUCT}

We might begin by asserting in simple (and perhaps simplistic) terms that anything that can be said about the process of monolingual communication can be said about bilingual communication - of which translation is a part - only more so!

The well-known model of communication [based on work on information theory in the late 1940s (Shannon 1949) and elegantly developed by Jakobson (1960)] applies, of necessity, to the translation process :

Figure 1

A model of communication

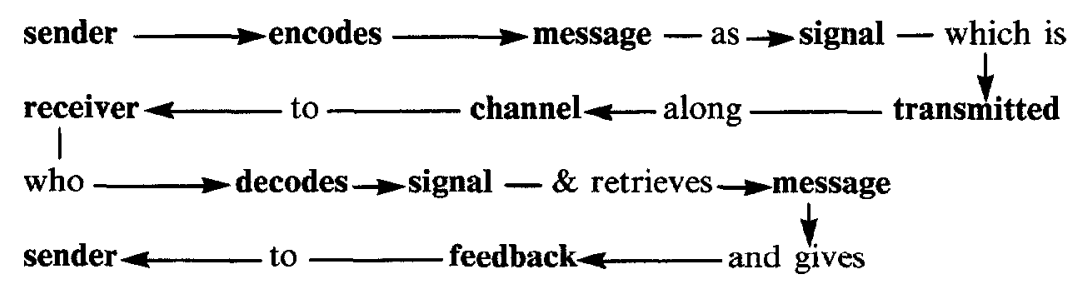

Translation, however, differs in three major respects from this general model :

1. The channel is limited to the visual. Translation, in contrast with interpreting, is concerned with written signals and texts rather than spoken.

2. Feedback between sender (the writer) and receiver (the reader) is absent or, where it does occur, likely to be subject to substantial delay.

3. The receiver decodes from code $A$ (the source language) and he re-encodes into code $B$ (the target language) for transmission to a receiver for whom the original sender may never have intended message.

In the first two instances, the distinction is, of course, shared by all forms of written communication but it is in the third respect that translation stands out as strikingly different. It follows, then, that a model of the translation process must not only be an 
adequate representation of the process of monolingual written text transfer but must, so to speak, be that $t$ wice and must, crucially, explain what happens at the switching point at which the message in $\mathbf{A}$ is converted into a signal (an encoded message) in B or, more correctly, at which a text in A is transmuted into a text in B.

The creation of an adequate model of this must, of necessity, be our primary goal. All else is secondary and derivative (ideally, axiomatically) from such a model. From the applied linguistic point of view, translation theory can be criticized for limiting its activites to the level of technique (the language teaching equivalent of classroom activities) or, at best, that of method (in language teaching terms, the equivalent of global collections of techniques; audio-visual method, direct method, etc.) when what is needed is an approach from which the rest would flow (see Bell 1981 : 75 f on such a view in language teaching).

Within the model, our attention needs first of all to be directed to an understanding of the processes of decoding (reading) and encoding (writing) and, within these, the nature of signal analysis, short-term memory, long-term memory and the structure of the long-term memory data-base with its input and output mechanisms will demand specification and explanation.

In what follows, we shall begin to model the decoding process in the terms we have just suggested. The limitation of discussion to decoding, and the omission of the encoding process, should not be taken to mean that we consider one to be, in any sense, primary and the other secondary, nor that we see one as no more than the mirror image of the other : far from it. We have imposed the restriction here merely in order to allow a relatively extended discussion of one half of the overall system. The second part must wait until another occasion.

\section{HUMAN INFORMATION PROCESSING} lowing :

A model of human information processing must, minimally, account for the fol-

1. That sensory stimuli received by the senses and transmitted to the brain for processing are chaotic rather than organized.

2. That the processing system is able to convert an input which consists of continuous stimuli into discrete units of data.

3. That even degraded or ambiguous stimuli can be (if only with partial success) processed.

4. That inherently meaningless signals can, on receipt, be converted into meaningful messages.

5. That enormous quantities of information can be processed, stored, retrieved and re-used with apparent ease and accuracy.

We recognize that accounting for such diverse and complex phenomena is far from simple and that in attempting to do so we are straying into the domains of physiology, neurology and psychology; domains in which we cannot claim any particular expertise (see Gregory 1977 for an convenient introduction). However, given that we feel obliged to make the attempt and, in so doing, fully acknowledge our debt to scholars in those fields, we offer a tentative outline of a model (Fig. 2 below).

\subsection{An outline of the model}

The model below (in Figure 2) outlines the three major systems involved in the processing of the information received by the brain through the activities of the senses. Three clear stages can be distinguished :

1. The reception, filtering, storage and initial processing of information by the sensory information system (the SIS is described in detail in 3.2 below). 
2. The final analysis, short-term storage and second filtering of the data by the short-term memory system (the STM is described in detail in 3.3 below).

3. The accessing of the long-term memory system - the database - and the integration of new information within it (the LTM is described in detail in 3.4 below).

Figure 2

Outline Model

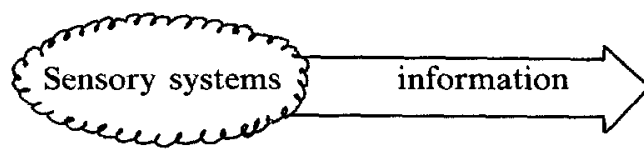

Sensory Information System filters, stores, records image, recognizes features \& patterns

Long-term Memory System input-output \& storage of data in the database Short-term Memory System codes \& stores data : accesses LTM database

\subsection{From sensation to perception}

The human brain, through the sensory systems of the body (1 in Fig. 3) - sight, hearing, taste, touch, smell - receives vast quantities of information (2 in Fig. 3 ) all the time and, as studies of sensory deprivation have shown (see, for example, Vernon 1963 : 117ff), appears to need such inputs in order to work adequately. Starved of data, the brain quickly begins to invent its own by hallucinating.

However, the brain cannot cope with the incoming stimuli in their entirety. Such a vast surge of information would overload the system (probably fatally) and this means that there must be, as the first stage of the processing system, a filter (3 Fig. 3) which can reject all but the information to which the system is paying attention at any given time. This selected information is next stored, very briefly (experimental evidence suggests about half a second ; hence the half-second "reaction time" in human beings) in a sensory information store (4 in Fig. 3) - a "sensory register" - which provides a complete and detailed record of the stimulus. This is either returned to the filter for disposal or passed on to the first of the processing systems ( $5 \mathrm{a}$ in Fig. 3) for recording as an image rather than the aggregate it is received as from the senses. The role of this stage is crucial, since it converts sensory stimuli, which are essentially chaotic and continuous, into a unit of information which is amenable to further processing. It is at this point that sensation becomes perception and we have moved from awareness alone to the first step in the process which leads to cognition.

\subsection{Sensory information system : feature \& pattern recognition}

Before continuing, perhaps we should make clear the source of the model we are using and explain some of its features. The model derives from that presented in Linsay \& Norman (1972: 98ff) in which 5a-d are, rather charmingly, termed demons, image, feature, cognitive and decision respectively. Perhaps, too, a word about "theories" and "models" would be appropriate here. 
Figure 3

Human Information Processing

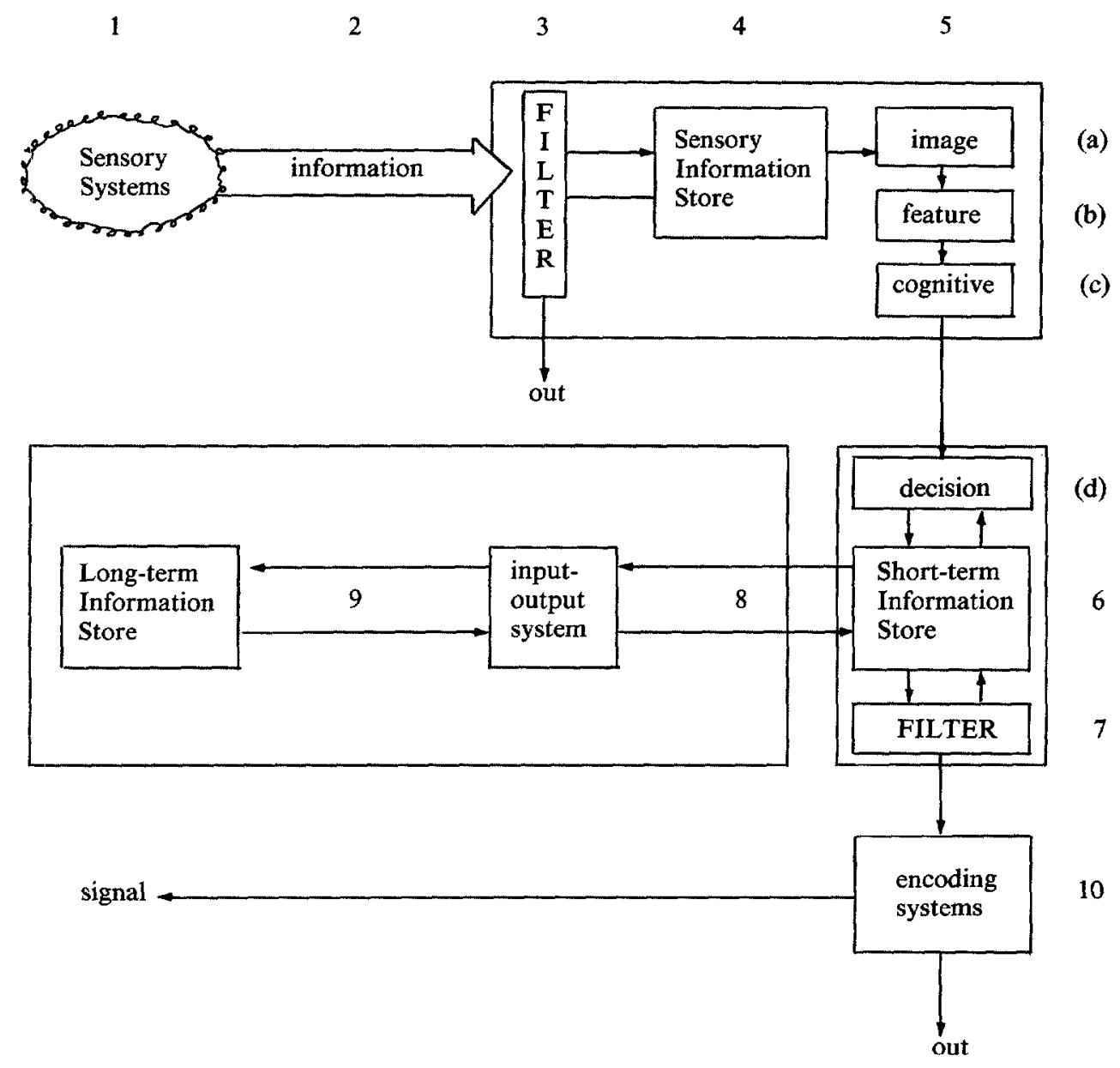

A theory is an explanation of a phenomenon, the perception of system and order in something observed. It exists (if at all ; philosophical debate has raged for two millenia over the existence of abstract entities) in the mind. It has no tangible manifestation. It is an idea. A model is, on the other hand, a physical embodiment of the theory. It is a tangible object which "stands for" the theory. It is important to realize that the model is a realization of the theory and not of the phenomenon. It is an "as if" which is suggested as a means of making it easier to grasp the explanation (i.e. the theory). The essential constraint on a model is that it should faithfully represent the theory that it "stands for". There is no requirement that a model should be "real" in the sense that it is to be thought of as actually representing the phenomenon itself, anymore than one would expect a model of Concorde to really fly at twice the speed of sound or to carry 
passengers ; all eating caviar and drinking champagne! We hope that no one thinks that we genuinely believe that there are little demons inside our heads. What the model does is to ask us to pretend that there are such demons - we could, though less interestingly, have called them either "subsystems" or "mechanisms" - each charged with specific information-processing tasks and we are asked to do this simply because it may be an amusing and memorable way of thinking about the process; no more than that. That said, we can continue.

The image demon ( $5 \mathrm{a}$ in Fig. 3) passes on the "image" to the feature demons ( $5 \mathrm{~b}$ in Fig. 3) who break it down into its constituent parts. The image is next passed on, plus its coding, to the cognitive demons ( $5 \mathrm{c}$ in Fig. 3) who match the coded features with patterns they already possess and pass on the image, its coding and its assigned pattern to the final level of analysis the ; decision demon ( $5 \mathrm{~d}$ in Fig. 3) who, being part of the shortterm memory system (the STM), will be described in the next section.

But first, to recapitulate the point we have reached. The original chaotic and continuous sensory input has been processed, first as a discrete image (a whole rather than an aggregate), next in terms of its distinctive features and then as a coherent pattern which, together with its feature coding, is passed on to the final level of a analysis in which a decision is reached on the status of the data (ambiguities are resolved, etc.). Here the sensory information system (the SIS) hands over to the short-term memory system (STM) for onward transmission of the information to the long-term memory system (LTM) and, as appropriate, to the output or encoding systems. But we run ahead of ourselves. We need, next, to describe the role of the STM and, initially, the function of the decision demon in it $^{5}$.

\subsection{Short-term memory : final analysis}

Next comes the acceptance of the coded pattern and the image itself by the decision demon who puts the information into the short-term information store (6 in Fig. 3), where it can be retained as a rapidly fading trace for some 30 seconds, assuming no new incoming data obliterates it or that it is kept in store for a longer period by rehearsal. The STM is not only limited in terms of the time during which it can store an item but also in terms of the amount it can hold at any time. Miller (1956) has demonstrated that the amount is $7+2$ "chunks" of information ; a "chunk" being a unit such as a number, a letter, a word. Strange as it may seem, the actual number of "bits" (in the information theory sense of the term) is not a significant factor here. A series such as bus, table, train, farm, shoe, water, hotel is, it appears, no more difficult to retain in the STM than the seemingly simpler series, $4,8,1,5,1,6,3$. The decision demon scans the data provided by the SIS, uses the STM to rehearse the information while it compares the new data with existing data in the LTM and then deals with it as appropriate (see below). An analogy might be to see the STM as in-tray in a busy office, constantly being filled with documents, some of which are put in the waste-paper basket (i.e. "filtered out" in the model ; 7 in Fig. 3), others are answered immediately (passed to the encoding system; 10 in Fig. 3) and yet others are passed on for filing (to 8 and 9 in Fig. 3).

"Successful" data are passed on from the STM to the LTM for storage and for later retrieval and use.

\subsection{Long-term memory : storage and recall}

The LTM, like any other information system, must contain :

1. an input-output system ( 8 in Fig. 3) which allows new data to be put into the storage system and existing stored data to be accessed and 
2. a database (9 in Fig. 3) in which information is stored in a manner which facilitates access.

An analogy might be the library catalogue and shelving system. The catalogue provides a classmark for each publication and the layout of the library itself ensures that publications on related topics - with, therefore, similar classmarks - are shelved together.

We shall argue (in section 3.5.2) that the library analogy is a powerful one, since it models for us not only the notion of the coding of incoming items and their storage but also the logical linkages which exist between items.

However, in two respects the LTM differs significantly from the library. First, and less importantly, the storage capacity of the database is, so far as we can tell, limitless and, second - and this makes a qualitative rather than a quantitative difference - the cataloguing system of the LTM can reorganize itself so as to maximize its efficiency in accessing and organizing data; something no library system can hope to do.

\subsubsection{Input-output system : coding the data}

We have already suggested that images are processed into their constituent distinctive features (5b) and labelled according to the pattern they match $(5 \mathrm{c})$ and that any ambiguity of feature recognition and matching is resolved (by $5 \mathrm{~d}$ ) before the image and its labelled features are passed on into the database. A simple example, using Roman numerals, may make the process clear.

1. The image (recorded at 5a) would consist of :

\section{V X L C M}

alone or in combination. We shall concentrate on single symbols in this example noting, in passing, that

2. Values are indicated by the combination of these symbols e.g.

$$
\mathrm{I}=1, \mathbf{I I}=2, \mathrm{III}=3, \mathbf{I V}=4 \text {, etc. }
$$

3. All seven symbols can be accounted for (by $5 b$ ) in terms of the possession or lack of no more than four features.

4. The distinctive features are
a) Vertical line
c) $\mathrm{V}$
b) Horizontal line
d) Curved line

5. The seven symbols can, therefore, be coded

I 1200

V 0010

X 0020

L $\quad 1100$

C 0001

D 1001

M 2010

Input into the STM would be in the form of

i) An image (from 5a) e.g. $M$

ii) Its coding (from $5 \mathrm{~b}$ ) ; 2010

7. The coding would act - just as the combination does to unlock a safe - as a "key" which permits access to the appropriate area of the database i.e. the location which contains the symbol $M$ and the information stored with it (see section 3.5.2 for a discussion of the structure of the database).

8. Matching of the image received with that stored (by $5 \mathrm{~d}$ ) would result in

i) The recognition of the new input as an example of existing stored $\mathbf{M}$. 
ii) The realization that the image has "called up" not one but two concepts i.e. the 13th letter of the Roman alphabet and the Roman numeral with the value of 1000 .

9. The disambiguation of the information would require the further attentions of the decision demon who would, given the context of $\mathbf{M}$ appearing together with words written in the Roman alphabet, match it with the phoneme $/ \mathrm{m} /$ or, conversely, in the context of Roman numbers, assign it the value 1000 .

There may appear to be some problems with the model :

i) Both $\mathbf{C}$ and $\mathbf{D}$ are coded as possessing a curved line (0001 and 1001 respectively) but the line faces in a different direction in each case.

ii) V X and $\mathbf{M}$ are all coded as possessing a "vee" (0010, 0020 and 2010 respectively), yet the "vee" is larger in the first case than in the second and third and, in the case of $\mathbf{X}$, there are two of them ; one inverted.

iii) Where more complex numbers are concerned, it may seem there is a potential ambiguity in the coding e.g. a series containing 1200, 0010, 1200 suggests a combination of one V and two I s i.e. III, IVI or VII.

The problems, as we shall see, are more apparent than real.

i) The feature demon in charge of recognizing curves does so, irrespective of the direction in which the curve faces, and merely reports the presence or absence of the feature. It is the task of the cognitive demons to match the reported curve with an appropriate pattern.

ii) Equally, the size of the "vee" is irrelevant to the feature demon charges with the recognition and reporting of that feature. Presented with the image $\mathbf{V}$, it will report "one vee", with X "two vees", with $\mathbf{M}$, "one vee", and will make its contribution to the coding with a declaration of one or two "vees" as appropriate.

iii) Where sequences are concerned, the problems suggested presents little difficulty. If the feature demons were to pass on a list of features which were open to more than one interpretation, the cognitive demons would match the image and its coding with their patterns and, if the ambiguity still remained, pass all the data on to the decision demon for judgment. In this example, IVI only matches M and no IIV pattern will be found. However, VII exists but that would match the image M far less well than IVI and the decision demon, faced by both, would undoubtedly decide in favour of $\mathbf{M}$.

A final point might be made. Initially, one would suppose, the learner of the Roman system would need to process longer sequences, numeral by numeral i.e. interpreting VI as $5+1=6$ and IV as $5-1=4$. In coding terms, the sequence 00101200 would be split up into its component numerals but, later, greater familiarity with the system would lead to the whole coding being used to give access to the cognitive information; VI $(00101200)=6$, without having to go through the slow and tedious arithmetical procedure given above.

If our model works for simple Roman numerals, if would follow that the difficulties we would face in the processing of longer numbers, Arabic numerals, Roman and non-Roman alphabets, ideographic systems, and hieroglyphics will be greater in degree rather than in kind and we shall have made a small step towards a specification of a part of the reading process (i.e. the decoding stage in the process of translation) of the process of translating. ory store.

Our next task is to describe the organization of the database ; the long-term mem- 


\subsubsection{The organization of the database}

We have been discussing human information processing in terms of "images" and "concepts" and it may have struck the reader that this is reminiscent of the two elements of the Saussurean linguistic sign ; the "image acoustique" and the "concept". Our use of the terminology has not been by chance. We propose to model the storage system of the LTM in a way which accepts the linguistic sign as the fundamental element of its structure but we shall extend de Saussure's notion from that of a flat, two dimensional sign to one with three dimensions, since we believe that such a change is necessary if we are to explain bilingual information processing.

To begin with, let us limit ourselves to some expansion of the term "concept".

Following fairly generally accepted views in epistemology, we see the concept as

a) Belonging to a class of concepts

b) Possessing certain characteristics

i) Properties which are inalienable characteristics e.g. "a leopard cannot change its spots" i.e. it is necessary for a leopard to have spots in order to be a leopard. The property relationship is polar i.e. a question of "has or has not".

ii) Supplying examples of itself which can be used to reify the concept e.g. "that is a leopard" i.e. the object I am indicating possesses characteristics which allow me to classify it as belonging within the class of concepts "leopard".

We can list these relationships :
a) Class
b) Property
c) Quality
that

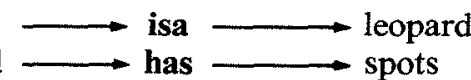
d) Example
a leopard
a leopard

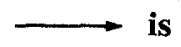
$\longrightarrow$ spots
that
isa
fierce
- leopard

In a) and d) the direction of the arrow is significant.
a) that
isa
(member of the class)

d) that $\longleftarrow$ isa $\longleftarrow$ (example of the class) $\longleftarrow$ leopard

In the database, we envisage the conceptual information as being stored in some manner analogous the the figure below

Figure 4

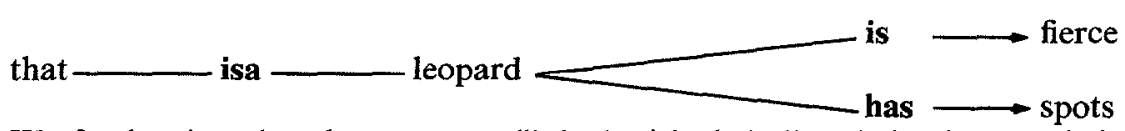

We further imagine the concepts (linked with their linguistic characteristics to make up linguistic signs) to be stored in the LTM in a way which not only provides linkages between them and their examples and characteristics but also cross-linkages such as inclusion (Fig. 5 below) and overlap or partial synonymy (Fig. 6 below) and, in sum, constituting the encyclopedic knowledge of the world possessed by the individual.

Figure 5

Inclusion

\begin{tabular}{|lll|}
\hline rose & flower & plant \\
\hline
\end{tabular}


Figure 6

\begin{tabular}{|l|} 
Overlap \\
\hline share \\
\hline
\end{tabular}

In addition, we assume these to be linkages of an essentially logical kind which permit the storage of information which is related to processes and events together with the participants involved and the circumstances of their occurrence. Such mechanisms (and they have been modelled in case grammars of various types) help account for the logical or semantic unity which underlines grammatically diverse sentences such as the dog bit the man the man was bitten by the dog bit the man, that's what the dog did, etc., etc. allowing us to deal with stylistic variation - productively and receptively - and giving us a further clue in our search for an explanation of the translation process.

\subsubsection{The linguistic sign in the bilingual LTM}

The notion of the linguistic sign (proposed by de Saussure in 1916) seems particularly relevant as a model for the storage units in the LTM. Extending the idea of the linguistic sign to the input and output of information to and from the LTM database (stage 8 in Figure 3), we might show the handling of a stimulus from the sensory systems being passed through progressively more sophisticated levels of analysis culminating in "understanding". Let us take as our stimulus the shape $\mathbf{L}$.

1. $L$ passes through the filter to the sensory information store and then to the image demon who records it a "L"

2. "' $L$ " is passed to the feature demons who record : one vertical line + one horizontal line : 1100

3. " $L " 1100$ is passed to the cognitive demons one of whom matches " $L$ " with the pattern $\mathbf{L}$.

4. L 1100 is passed to the decision demon who finds no ambiguity, since he is analysing in the context of a series Roman numerals, and uses the code -1100 - to "call up" the address of the concept.

5. 1100 displays the sign

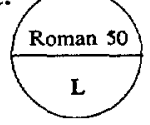

6. The decision demon "understands" and uses the information in whatever way is appropriate ; encoding it, rejecting it, etc.

All very well, one might say, but what of the bilingual ? Does the bi- (or multi-) lingual store the same information in different databases depending on the language ? If so, it seems strikingly inefficient to have the same concept represented again and again merely because its linguistic realizations are different. If not, what happens to the indivisibility of the sign? Not only does this appear to be a substantial problem in relation to bilingualism but also, though to a lesser extent, in monolingual usage where lexical "synonyms" occur.

The problem, we would suggest, is a pseudo-problem (not that we thought that in Bell $1976: 120 f$ ) and is, to a very large degree, no more than an artifact of the modelling we are engaged in. We suspect that the "problem" derives from the difficulty of visualiz- 
ing a three-dimensional object on a two-dimensional piece of paper ! In short, we now see the sign in the bilingual mind as a polyhedron with the concept inside it and, on each of the faces, an appropriate realization in one of the languages (see Figs. 7 and 8 in which the linguistic sign for the concept "tree" is used as an example with six languages involved; English, Finnish, French, German, Italian and Russian).

\section{Figure 7}

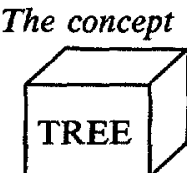

\section{Figure 8}

The linguistic sign

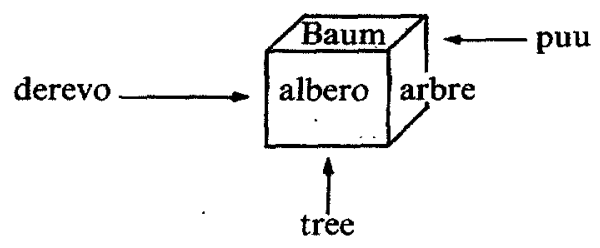

In order to integrate such a notion as the polyhedron sign into our existing model of recall from the LTM database, we need to imagine the use of the coding as a key to reveal the container of the concept but, as yet, with no indication as to which face should be presented to us. What must be added is something like an extra digit or two which would "rotate" the sign so as to show the correct face to the scanning device. This is no more complex or far-fetched an idea than that of international direct dialling (IDD), where a number consists of

for example

$$
\text { IDD code + area code + local code + subscriber's number }
$$

$$
\begin{aligned}
& 33+01+622+1559 \\
& \text { (France) }+ \text { (Paris) }+ \text { (St-Cloud) + Pierre X }
\end{aligned}
$$

Perhaps we should reassert the point made earlier about models. No claims are being made for this as a representation of the actual processes involved. The purpose of the model is heuristic i.e. to facilitate discussion of the problem. Even so, we would suggest that this model does go some way to explaining the "tip-of-the-tongue" phenomenon (see Brown 1968 for an interesting discussion) and the not infrequent experience of the bilingual when, not only can one not recall the appropriate word in a particular language, but finds oneself incapable of recalling an appropriate word in any language. What we tend to say, interestingly enough, is "I can't quite see it". How extraordinary that de Saussure should have talked of an acoustic image. The polyhedron has, as it were, rotated so as to present us, not with a face, but with an edge and has "stuck" like that.

Apart from the convenience of displaying the centrality of the concept in each sign, the model we are proposing has a number of additional advantages over the tradi- 
tional two-dimensional Saussurian sign. It shifts the debate on compound, co-ordinate and other types of bilingualism firmly into the area of the "switching mechanism (long recognized as the key issue) and, by recognizing that any language user possesses a repertoire of codes which differs quantitatively and qualitatively from those of other users and that it will change over time, the notion of the polyhedron sign builds in a flexibility which can facilitate the modelling of variation and change.

To take a personal and concrete example. My own sign for $\mathrm{H} 2 \mathrm{O}$ must be a polyhedron with, at least, seven sides to accommodate the English, French, German, Hindi, Italian, Polish and Spanish words I know for expressing the concept. Conversely, for the concept ketch (a small two-masted sailing vessel with the shorter of the two masts in the stern in front of the rudder post), I need no more than the traditional twodimensional sign with a single realization for the concept. I have no idea what word might be used in any other language. Clearly, I can increase the number of faces on each polyhedron as I learn more lexical items (after a month in Brazil, I have just added several Portuguese items to my existing linguistic signs) or the faces can decrease in number as I progressively forget items (after five years, most of the items I knew in Bahasa Malaysia have disappeared).

\subsection{Conclusion}

It is perhaps pretentious to head the final part of this paper "conclusion". All we have achieved, at best, is a small beginning to a somewhat different way of looking at the bewildering phenomenon of translation. We have in no sense reached a conclusion.

There are major questions demanding consideration, even within what has been discussed so far. What is the exact function of each stage in the model and the precise specification of the linkages between them ? Far more detail is required, for example, on the structure of the database. How does it deal with ambiguity, with synonymy, with connotative rather than denotative meaning? Where does the database store grammatical sign? How do lexical and semantic fields operate? How are texts structured so as to be not only semantically cohesive but also pragmatically coherent ? Is there some kind of "thesaurus" and is this distinct from or part of the "encyclopedia" of world knowledge? A virtually endless series of questions, and all before we consider the other side of the coin : encoding.

\section{Notes}

1. Notwithstanding denials from Basnett-McGuire $(1980: 37)$ who argues "The purpose of translation theory ... is to reach an understanding of the processes undertaken in the act of translation and, not, as is so commonly misunderstood, to provide a set of norms for effecting the perfect translation. In the same way, literary criticism does not seek to provide a set of instructions for producing the ultimate poem or novel, but rather to understand the internal and external structures operating within and around a work of art".

2. Linguistics is defined broadly in this paper to include not only the syntactic and semantic "core" of the linguistic code - the specification of rules of usage - but also the pragmatics of use and the psycho- - and sociolinguistic constraints and conventions under which use takes place.

3. With the almost unique exceptions of Nida (1964) and Catford (1965).

4. Hence the attempts to introduce "diary studies" into the teaching of translation theory (see Bell in press).

5. In section 3.4.2 we run through the model applying it to the processing of Roman numerals.

\section{BIBLIOGRAPHY}

BASNETT-McGUIRE, S. (1980) : Translation Studies, Methuen.

BELL, R.T. (1976) : Sociolinguistics, Batsford.

BELL, R.T. (1981) : An Introduction to Applied Linguistics, Batsford.

BELL, R.T. \& L. O'DWYER (in press) : "Diary Studies : A New Way of Tapping the Process of Translation". 
BROWN, R. (1968) : "The 'Tip of the Tongue' Phenomenon", Jou Verbal Learning \& Verbal Behaviour, 5:4, pp. 235-337. Repr. R. Brown (1970).

BROWN, R. (1970) : Psycholinguistics, Free Press.

CATFORD, J.C. (1965) : A Linguistic Theory of Translation, Oxford:

GREGORY, R.L. (1977) : Eye and Brain: The Psychology of Seeing, 3rd revised ed., Weidenfeld \& Nicolson. JAKOBSON, R. (1960) : "Closing Statement : Linguistics \& Poetics", in T.A. Sebeok, Ed., pp. $350-377$. LINSAY, P.H. \& D.A. NORMAN (1972) : Psychology : An Introduction, 2nd ed., Harcourt, Brace. MILLER, G.A. (1967) : The Psychology of Communication, Penguin.

NEWMARK, P.P. (1982) : Approaches to Translation, Pergamon.

NIDA, E.A. (1964) : Towards a Science of Translating, Brill.

de SAUSSURE, F. (1916) : Cours de linguistique générale, Payot.

SEBEOK, T.A., Ed. (1960) : Style in Language, MIT.

SHANNON, C.E. and W. WEAVER (1949): The Mathematical Theory of Communication, Univ. Illinois. TYTLER, A. (1791) : Essay on the Principles of Translation, Dent.

VERNON, J. (1963) : Inside the Black Room, Penguin.

WILSS, W. (1982) : The Science of Translation, Günter Narr. 